Research Article

\title{
Hyaluronic Acid-IR780 Nanoparticles for Photothermal Ablation in Orthotopic Renal Cancer
}

\author{
Guangxiang Liu, Tingsheng Lin, Qing Zhang, Shengjie Zhang, Changwei Ji, Shiwei Zhang, \\ and Hongqian Guo
} Department of Urology, Drum Tower Hospital, Medical School of Nanjing University, Institute of Urology, Nanjing University,
Nanjing, Jiangsu, China

Correspondence should be addressed to Hongqian Guo; dr.ghq@nju.edu.cn

Received 3 September 2019; Accepted 24 March 2020; Published 16 April 2020

Academic Editor: Katerina Aifantis

Copyright (c) 2020 Guangxiang Liu et al. This is an open access article distributed under the Creative Commons Attribution License, which permits unrestricted use, distribution, and reproduction in any medium, provided the original work is properly cited.

\begin{abstract}
Renal cancer is one of the most common malignancies in urological tumors; it is necessary to develop a noninvasive and highly targeted thermal ablation method for the treatment of renal tumors. IR780 has been shown to be an effective photothermal agent for tumor thermal ablation. This study was designed to explore the feasibility of applying hyaluronic acid-IR780 nanoparticles (HA-IR780 NPs) for targeted thermal ablation of renal tumors using an in situ renal tumor model. The size of the nanoparticles was $172 \pm 8.2 \mathrm{~nm}$; it showed a stable spherical nanostructure with good monodispersity. HA-IR780 NPs showed high photothermal efficiency, with the $20 \mu \mathrm{g} / \mathrm{mL}$ HA-IR780 NPs showing a maximum temperature increase of $24.5^{\circ} \mathrm{C}$ with $6 \mathrm{~min}$ of $808 \mathrm{~nm}$ laser irradiation. NIR imaging showed that the nanoparticles exhibited targeted accumulation in renal tumor tissues. The treatment efficacy of the HA-IR780 NPs showed that renal tumors treated with the HA-IR780 NPs and laser irradiation were effectively ablated. Our results showed that the HA-IR780 nanoparticles that mediated the photothermal effect could generate tumor-specific heat for the destruction of a renal tumor in a minimally invasive way, which provides a novel strategy for thermal ablation of renal tumors.
\end{abstract}

\section{Introduction}

Renal cancer is one of the most common malignancies in urology. Radical nephrectomy and nephron-sparing surgery are the major treatments for renal cancer [1-5]. In recent years, radiofrequency ablation (RFA) has been widely used in the treatment of renal tumors, due to its minimally invasive and high treatment efficiency. RFA is a process where needle electrodes are placed in the tumor tissues; the radiofrequency energy was output by the needle to generate heat with a local temperature of $95 \sim 100^{\circ} \mathrm{C}$ and damage the tumor lesions [6-9]. RFA has many advantages when compared with traditional surgery, but it also has many disadvantages: nonuniform heat production in the tumor, tumor dissemination through the RFA catheter, and adjacent organs damaged by high temperature $[8,10]$. Therefore, it is necessary to develop a noninvasive and highly targeted thermal ablation method for the treatment of renal tumors.

Photothermal therapy (PTT) is an effective method for treating tumors; photosensitizers can generate heat during laser irradiation, efficiently killing tumor cells and resulting in the ablation of tumors $[11,12]$. When compared with radiofrequency ablation, photothermal therapy can uniformly generate heat at targeted tumor sites, is noninvasive, and provides a new strategy for thermal ablation of renal cancer [13-16]. Hyaluronic acid (HA) is one of the components in the human body and plays an important role in modulating the immune system and scavenging ROS. HA has good water solubility, biodegradation, low toxicity, and low immunogenicity; it is a good carrier for drug delivery [17-24]. IR780 is a lipophilic, cationic small molecule nearinfrared (NIR) photosensitive agent that belongs to the 

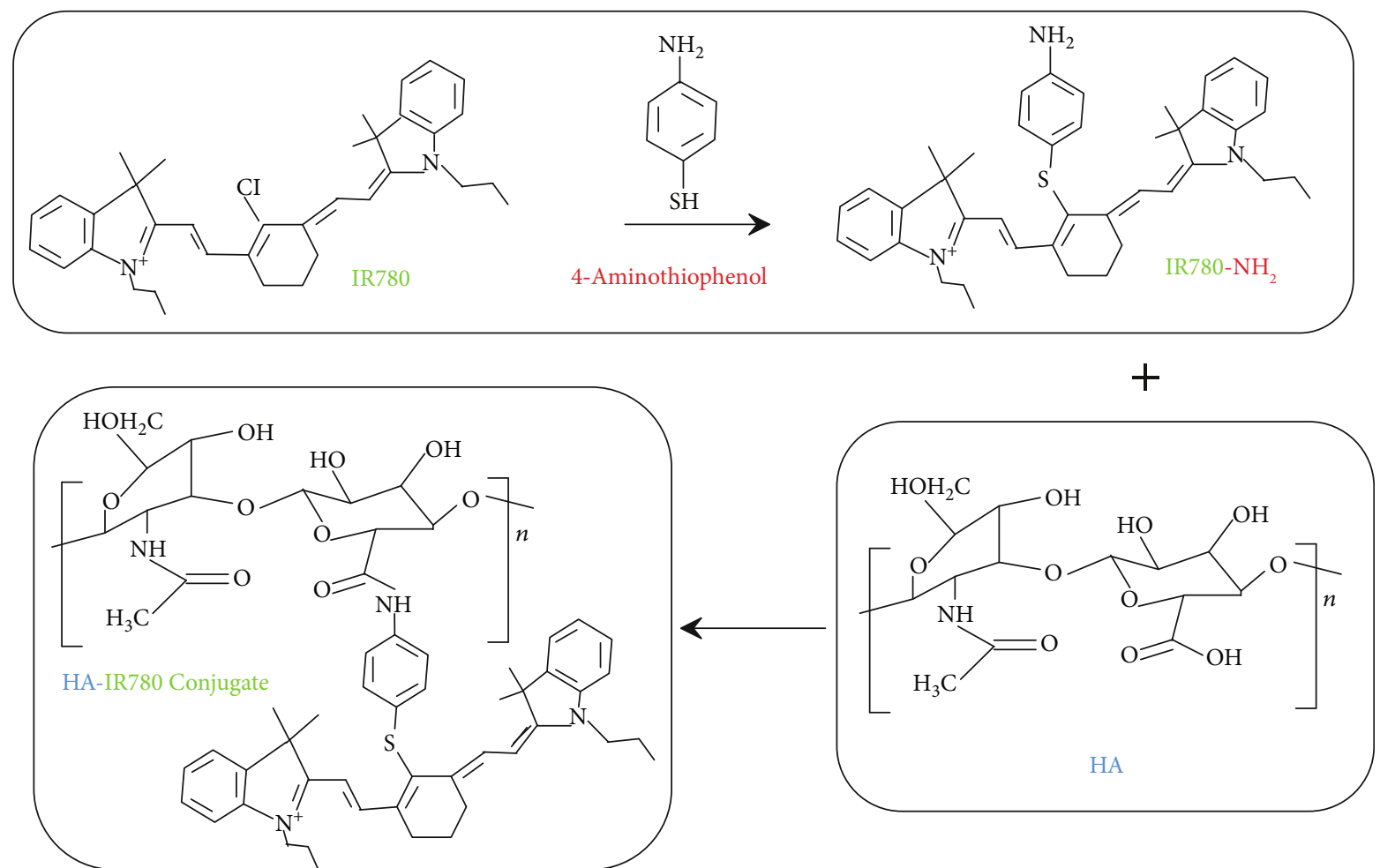

Scheme 1: The synthetic process of HA conjugates.

near-infrared heptarchy cyanine dye group and has a molecular weight of $667 \mathrm{Da}$; it also can generate heat under NIR laser irradiation $[25,26]$.

In this study, we prepared hyaluronic acid-IR780 nanoparticles (HA-IR780 NPs) (shown in Scheme 1) using hyaluronic acid as the carrier according to our previous reports [15]. We characterized the HA-IR780 NP nanoparticles by dynamic light scattering (DLS), transmission electron microscope (TEM), and UV-visible spectrophotometer. The NPs were irradiated with an NIR laser to investigate its photothermal properties. The cellular uptake of the NPs in renal cancer cells was performed, and photothermal toxicity of the HA-IR780 NPs in renal cancer cells was also investigated. We established a stable orthotopic renal tumor model, the biodistribution of the NPs was observed by NIR imaging, and the antitumor efficacy of the HA-IR780 NPs in the orthotopic renal tumor model was evaluated.

\section{Materials and Methods}

2.1. Materials. The following were the materials used: IR780 (Sigma-Aldrich, USA), 1-ethyl-3(3-dimethylaminopropyl) carbodiimide (EDC), N-hydroxysuccinimide (NHS), amino thiophenol (ATP) (J\&K Scientific Ltd., China), hyaluronic acid (Mw $=10 \mathrm{kDa}$ ) (Nanjing Sunlida Biological Technology Co., Ltd., China), cell counting kit-8 (CCK-8) (Dojindo Laboratories, Japan), N,N-dimethylformamide (DMF), and formamide (Shanghai Lingfeng Chemical Reagent Co., Ltd., China). All of the Balb/c mice (male, 6 8 weeks, 18 20 g) were from Yangzhou University Medical Center.
2.2. Preparation of the HA-IR780 NPs. For the preparation method of HA-IR780 NPs, refer to our previous report [15]. Briefly, the mixture of 4 -aminothiophenol $(15 \mu \mathrm{mol})$ and IR780 $(7.5 \mu \mathrm{mol})$ dissolved in DMF was stirred at room temperature overnight to obtain IR780- $\mathrm{NH}_{2}$. Then, NHS $(50 \mu \mathrm{mol})$, EDC $(50 \mu \mathrm{mol})$, and HA $(5 \mu \mathrm{mol})$ were dissolved in formamide solution to get HA-NHS ester. The mixture of HA-NHS ester and IR-780- $\mathrm{NH}_{2}$ (IR780 : $\left.\mathrm{HA}=1 \mathrm{~mol}: 1 \mathrm{~mol}\right)$ was stirred at room temperature overnight to get amphiphilic HA-IR780 conjugates. The unreacted IR780 was removed by using Sephadex LH-20 (GE Healthcare). Finally, HA-IR780 conjugates were dispersed in PBS to obtain the HA-IR780 nanoparticles. The nanoparticles were purified using an ultrafiltration membrane (molecular weight $\sim 30 \mathrm{kDa}$ ) to remove the free small molecules; then, the nanoparticles were filtered through a filter membrane $(0.22 \mu \mathrm{m})$. Finally, the HA-IR780 NP dispersions were stored at $4^{\circ} \mathrm{C}$.

2.3. Characterization of the HA-IR780 NPs. TEM (Hitachi H7650) and DLS (Brookhaven Instruments Corporation, USA) were used to measure the diameter and morphology of the HA-IR780 NPs. The average diameter of HA-IR780 NPs in

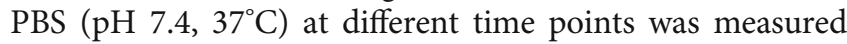
by DLS to investigate its stability. The UV-vis spectra (UV2450, Shimadzu Corporation) of HA-IR780 NPs were also measured. The HA-IR780 NPs $(5,10$, and $20 \mu \mathrm{g} / \mathrm{mL}$ ) were irradiated with the NIR laser $\left(808 \mathrm{~nm}, 1 \mathrm{~W} / \mathrm{cm}^{2}\right)$ to investigate its photothermal properties.

2.4. In Vitro Cellular Uptake Behaviour of the HA-IR780 NPs. The renal cell lines (RENCA) were cultured in medium (1640 


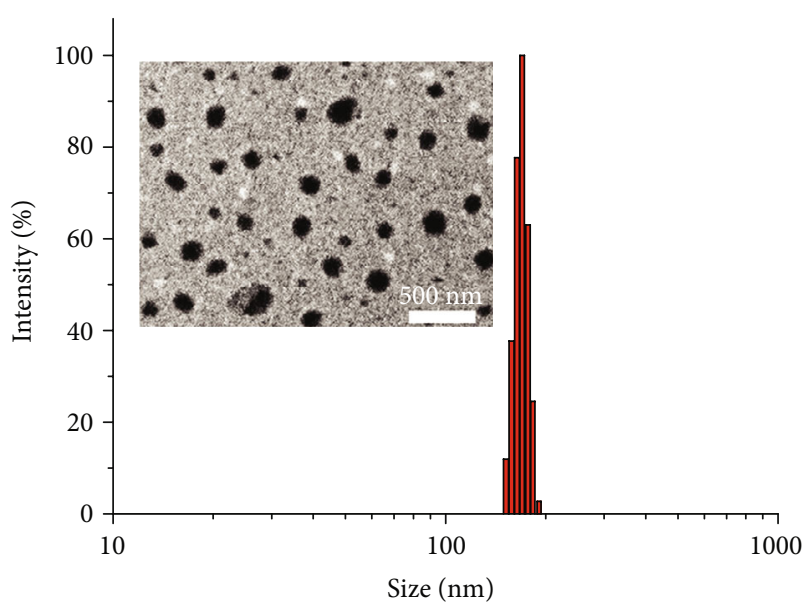

(a)

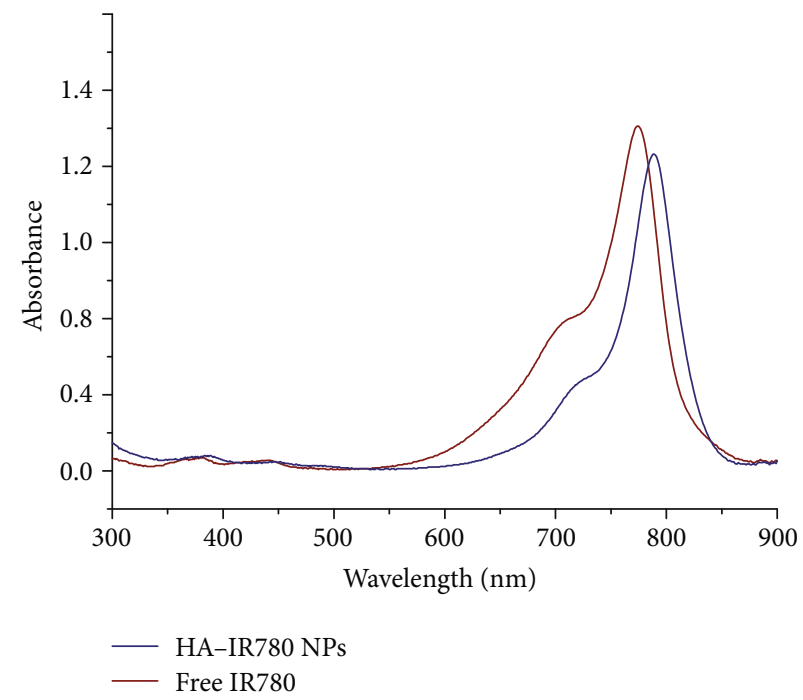

(c)

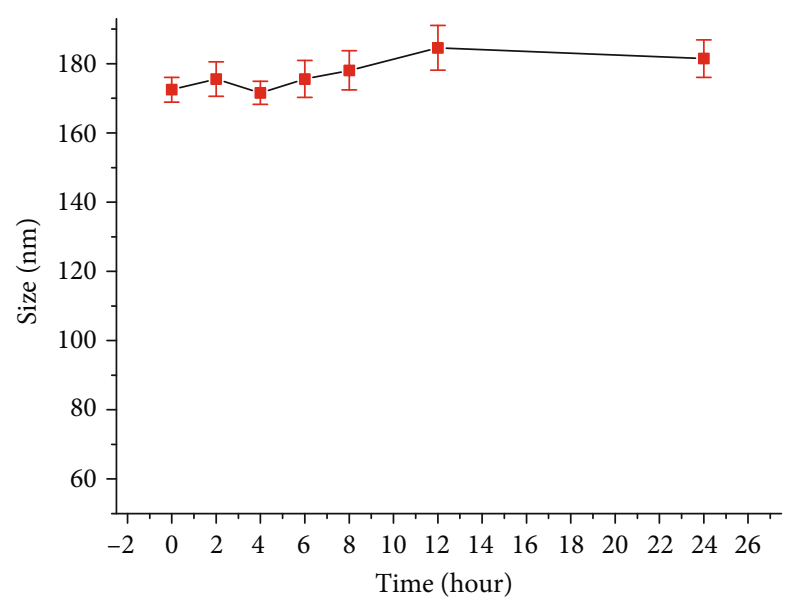

(b)

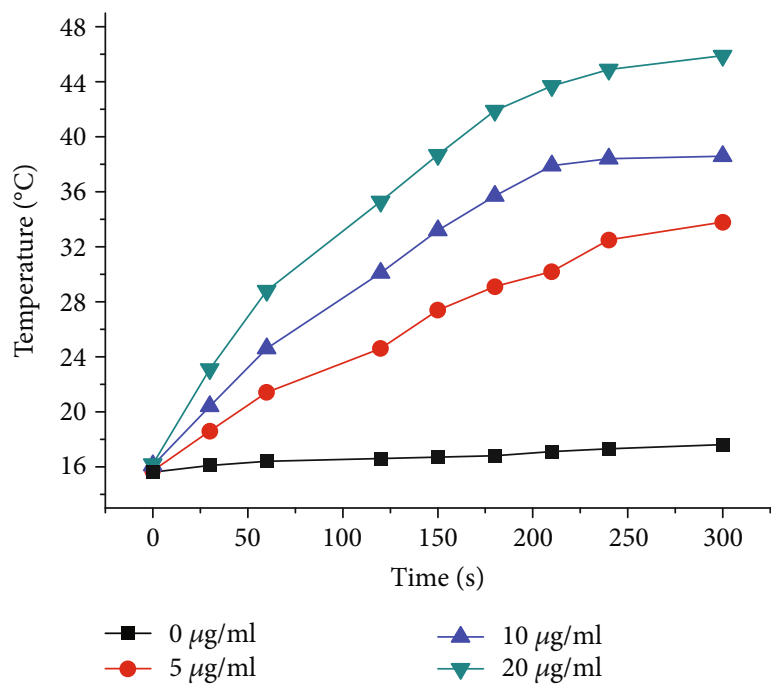

(d)

FIgURE 1: Characterization of the HA-IR780 NPs: (a) size distribution and TEM image of the HA-IR780 NPs, (b) size stability of the HAIR780 NPs, (c) UV-vis-NIR absorbance spectrum of the HA-IR780 NPs, and (d) photothermal effect of the HA-IR780 NPs in vitro.

Gibco medium, 10\% foetal bovine serum, 1\% streptomycin, and $1 \%$ penicillin) in a $\mathrm{CO}_{2}$ incubator at $37^{\circ} \mathrm{C}$. To evaluate the cellular uptake of HA-IR780 NPs, the cells were seeded in a 12 -well compartment glass $\left(2 \times 10^{4} /\right.$ well $)$. After culturing for $24 \mathrm{~h}$, the medium was replaced with fresh medium containing the HA-IR780 NPs $(2 \mu \mathrm{g} / \mathrm{mL})$. Then, the medium was removed, and cells were washed with PBS after $3 \mathrm{~h}$ of coincubation. Subsequently, cells were fixed with $4 \%$ paraformaldehyde, and the cell nucleus was stained with DAPI. The fluorescence (DAPI and IR780) in the cells was observed using a confocal laser scanning microscope (CLSM, Leica TCS SP5, Germany; emission: $700 \sim 800 \mathrm{~nm}$, excitation: $633 \mathrm{~nm}$ ).

2.5. Photothermal Toxicity of the HA-IR780 NPs In Vitro. To evaluate the photothermal cytotoxicity of the HA-IR780 NPs with NIR laser irradiation, the RENCA cells were seeded in a 96-well compartment glass $\left(1 \times 10^{4} /\right.$ well $)$. After culturing for $24 \mathrm{~h}$, the medium was replaced with fresh medium containing different concentrations of HA-IR780 NPs. Then, the medium was removed after $3 \mathrm{~h}$ of coincubation, cells were washed with PBS, and the fresh medium was added. Subsequently, the cells were irradiated with the NIR laser $\left(808 \mathrm{~nm}, 1 \mathrm{~W} / \mathrm{cm}^{2}\right)$ for $2 \mathrm{~min}$. After culturing for $24 \mathrm{~h}$, the CCK-8 assay was performed to evaluate the cell viability.

2.6. The Establishment of an Orthotopic Renal Tumor Model in Mice. Balb/c mice were used according to the protocols approved by the Nanjing University Laboratory Animal Center. Briefly, 0.2 mL RENCA cells $\left(1 \times 10^{7}\right)$ in PBS were injected into the right flank of the mice subcutaneously. After the tumor grew to about $300 \mathrm{~mm}^{3}$, the tumor was removed from the mice and cut into small tumor tissue blocks $\left(\sim 1 \mathrm{~mm}^{3}\right)$. Then, to establish the orthotopic renal cancer model, mice were anesthetized and fixed on an operating floor. A small left flank incision was made to expose the kidney; one tumor block was seeded into the subcapsular space of the kidney; then, the incision was sutured with 5-0 silk. After few days, the orthotopic renal tumor was confirmed with the naked eye by exposing the kidney directly. 
2.7. In Vivo Biodistribution of the HA-IR780 NPs. The IR780 fluorescent signal was detected with the IVIS Lumina imaging system (Xenogen Co., USA) to evaluate the distribution of the HA-IR780 NPs in the orthotopic renal tumor model. The mice were intravenously injected with HA-IR780 NPs $(2.5 \mathrm{mg} / \mathrm{kg})$ or PBS; NIR imaging (emission spectrum: $780-$ $900 \mathrm{~nm}$, excitation wavelength: $735 \mathrm{~nm}$ ) was performed at $2 \mathrm{~h}, 12 \mathrm{~h}, 24 \mathrm{~h}$, and $48 \mathrm{~h}$ after injection. The distribution of the HA-IR780 NPs in the tumor and major organs (liver, lung, kidney, spleen, and heart) was evaluated. The mice were sacrificed $48 \mathrm{~h}$ after the injection, and the main organs were isolated; NIR imaging of major organs was performed. IVIS Living Imaging Software was used to analyze the obtained NIR images, and semiquantitative biodistribution analysis was also performed.

2.8. Photothermal Therapeutic Efficacy of the HA-IR780 NPs in an Orthotopic Renal Tumor Model. To measure the intratumoral temperature, the HA-IR780 NPs (5 mg/kg IR780) or PBS were intravenously injected into orthotopic renal cancer-bearing mice. 24 hours after injection, mice were anesthetized and the renal tumor was exposed by a small left flank incision; the intratumoral temperature changes under the laser irradiation $\left(808 \mathrm{~nm}, 1 \mathrm{~W} / \mathrm{cm}^{2}\right)$ were recorded. To investigate the treatment efficacy of the NPs, orthotopic renal cancer-bearing mice were divided into four groups (4 mice in each group), including the PBS group, PBS with laser irradiation group, HA-IR780 NP group, and HA-IR780 NPs with laser irradiation group. Mice were intravenously injected with HA-IR780 NPs ( $5 \mathrm{mg} / \mathrm{kg}$ IR780) or PBS. The tumors were irradiated with the NIR laser $\left(808 \mathrm{~nm}, 1 \mathrm{~W} / \mathrm{cm}^{2}\right)$ for 8 min after $24 \mathrm{~h}$ injection (day 0 ). The body weight was measured every two days. The mice were sacrificed at day 12, photographs of kidneys and tumors were taken with a camera, the tumor size was measured, and the kidneys were collected for H\&E staining.

2.9. Statistical Analysis. A two-sided Student $t$-test for two groups and one-way ANOVA for multiple groups were used for statistical analysis. $P<0.05$ was considered statistically significant.

\section{Results and Discussions}

3.1. Preparation and Characterization of the HA-IR780 NPs. The HA-IR780 nanoparticles were prepared according to our previous reports. The HA was chemically conjugated with IR780 to obtain a HA-IR780 conjugate via 4aminothiophenol. HA-IR780 conjugate is amphiphilic, due to its hydrophobic IR780 segment and hydrophilic HA segment. Therefore, the HA-IR780 conjugates self-assembled into nanoparticles with a hydrophobic core and a hydrophilic shell in aqueous solutions. From Figure 1(a), DLS showed that the particle size of the HA-IR780 nanoparticles was evenly distributed between 150 and $180 \mathrm{~nm}$ with an average particle size of $172 \pm 8.2 \mathrm{~nm}$. TEM revealed that the NPs were spherical in shape with good monodispersity. Figure 1(b) shows that the stability of the HA-IR780 NPs and the size of the NPs remained consistent $(\sim 180 \mathrm{~nm})$ at 24 hours.

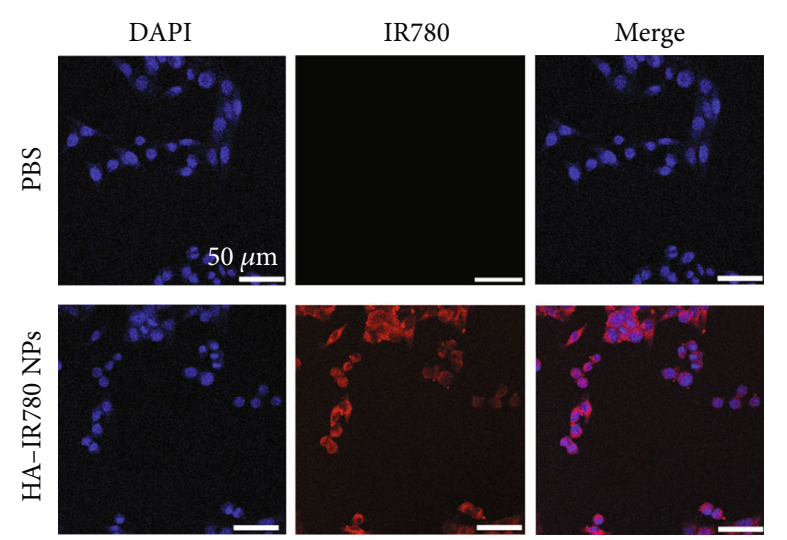

FIGURE 2: Cellular uptake of the HA-IR780 NPs. Confocal images of the RENCA cells after $3 \mathrm{~h}$ of incubation with the HA-IR780 NPs (blue: DAPI, red: IR780).

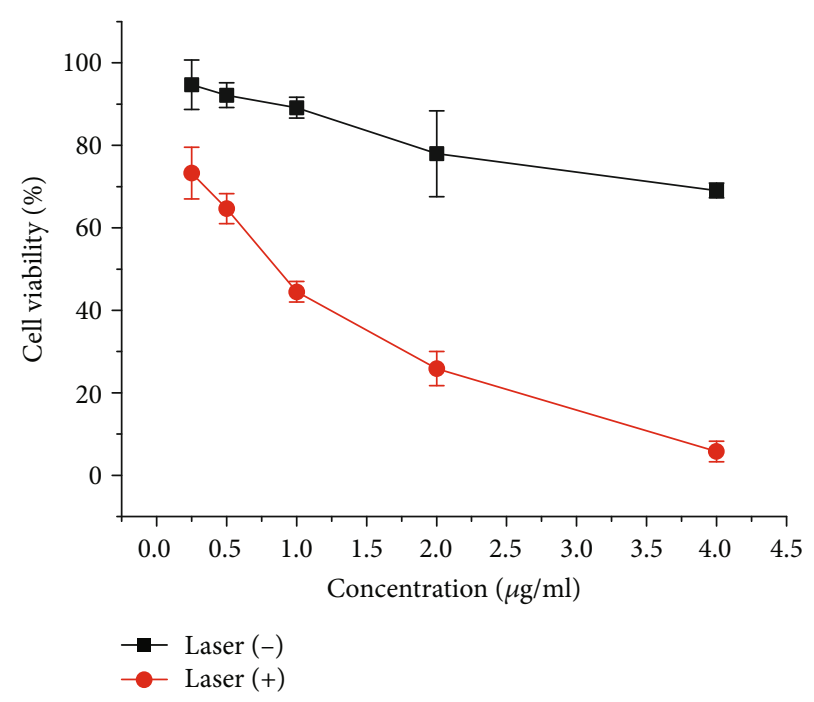

FIgURE 3: In vitro photothermal therapy of the HA-IR780 NPs. The cytotoxicity of the HA-IR780 NPs in the RENCA cells with or without laser irradiation $\left(808 \mathrm{~nm}, 1 \mathrm{~W} / \mathrm{cm}^{2}\right)$ for $2 \mathrm{~min}$.

Figure 1(c) shows UV/vis absorption bands between 706 and $836 \mathrm{~nm}$ of the HA-IR780 NPs with a maximum wavelength at $796 \mathrm{~nm}$ in ethanol. When compared with free IR780, the absorption peak of the HA-IR780 NPs was a $10 \mathrm{~nm}$ redshift. This is because the structure of IR780 was changed by chemical modification. Figure $1(\mathrm{~d})$ shows the photothermal efficiency of the HA-IR780 NPs in vitro. When the concentration of HA-IR780 NPs was 5,10 , and $20 \mu \mathrm{g} / \mathrm{mL}$, the temperature increase was $15.8^{\circ} \mathrm{C}, 20.3^{\circ} \mathrm{C}$, and $24.5^{\circ} \mathrm{C}$ with $6 \mathrm{~min}$ of $808 \mathrm{~nm}$ laser irradiation $\left(1 \mathrm{~W} / \mathrm{cm}^{2}\right)$, respectively. The tumor cells can receive irreversible damage from the NPs with this temperature increase.

3.2. In Vitro Cellular Uptake Behaviour of the HA-IR780 NPs. The cellular uptake of the HA-IR780 NPs by the RENCA cell lines that was observed by confocal microscopy is shown in Figure 2. The cancer cells treated with the HA-IR780 NPs 


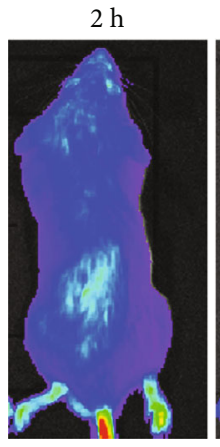

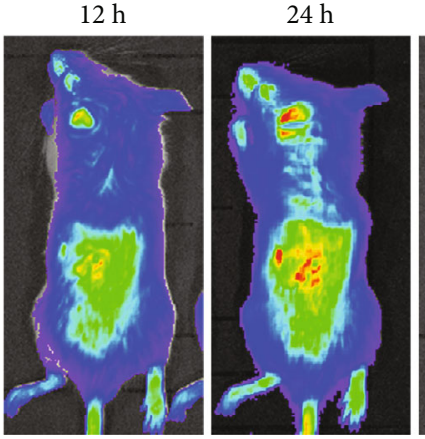

(a)

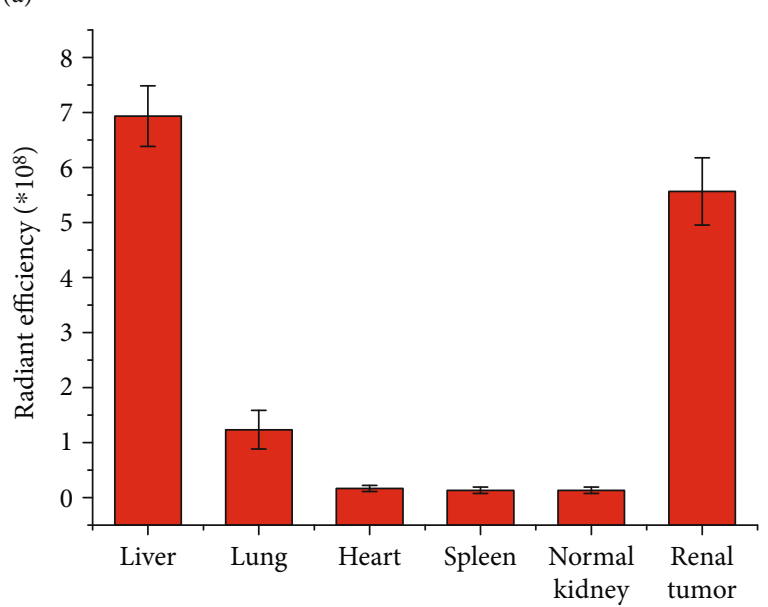

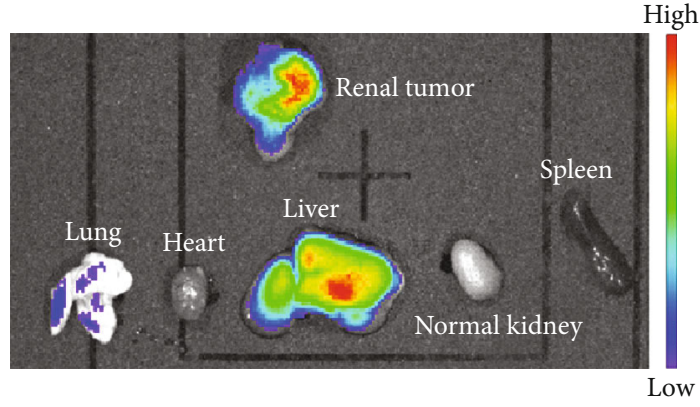

(b)

(c)

FIGURE 4: In vivo biodistribution of HA-IR780 NPs in orthotopic renal tumor-bearing mice: (a) NIR imaging of orthotopic renal tumorbearing mice injected with HA-IR780 NPs; (b) fluorescence images of the major organs and renal tumor at $48 \mathrm{~h}$ after injection of the NPs; (c) semiquantitative biodistribution analysis of the HA-IR780 NPs in mice.

$(2 \mu \mathrm{g} / \mathrm{mL})$ showed a strong red colour in the cytoplasm, and the cancer cells that were treated with PBS showed no red colour in the cytoplasm. This indicated that a large number of the HA-IR780 NPs were taken up by the cancer cells.

3.3. Photothermal Toxicity of the HA-IR780 NPs In Vitro. The photothermal therapy effect of the HA-IR780 NPs in the RENCA cells was evaluated. Figure 3 shows the remarkable cytotoxicity of the HA-IR780 NPs when the cells were exposed to $808 \mathrm{~nm}$ laser irradiation; especially at IR780 concentrations of $4 \mu \mathrm{g} / \mathrm{mL}$, the survival rate of the RENCA cells was only $3.1 \%$. Without laser irradiation, the control group showed low cytotoxicity of the HA-IR780 NPs on the RENCA cells. The results suggested that the HA-IR780 NPs can effectively kill cancer cells via the photothermal effect.

3.4. In Vivo Biodistribution of the HA-IR780 NPs. We established the orthotopic renal tumor model in Balb/c mice. The distribution of the HA-IR780 NPs in orthotopic renal tumor-bearing mice was evaluated with the IVIS Lumina imaging system. Figure 4 shows the NIR fluorescence of the HA-IR780 NPs that was detected in the tumor region (left kidney) at $2 \mathrm{~h}$ postinjection. The HA-IR780 NPs tended to accumulate in the tumor region over time, with remarkable accumulation in the tumor region after $24 \mathrm{~h}$ and $48 \mathrm{~h}$ injec- tion. The distribution of the HA-IR780 NPs in the tumor and major organs (liver, lung, kidney, spleen, and heart) was evaluated at $48 \mathrm{~h}$ after the injection. The results showed that the tumors had a stronger NIR fluorescence signal, which confirmed the accumulation of the HA-IR780 NPs in the tumor. The results indicated excellent tumor-targeting property of the HA-IR780 NPs. This excellent tumortargeting property of the NPs is probably due to the EPR effect on the tumor of the NPs.

\subsection{Photothermal Therapeutic Efficacy of the HA-IR780 NPs} in an Orthotopic Renal Tumor Model. Next, we measured the intratumoral temperature under the laser irradiation $\left(808 \mathrm{~nm}, 1 \mathrm{~W} / \mathrm{cm}^{2}\right)$ at $24 \mathrm{~h}$ after the intravenous injection of the NPs (Figure 5(b)). Temperature changes in the tumor area were measured during $8 \mathrm{~min}$ laser irradiation. The temperature of the tumor area was significantly increased in the HA-IR780 NP groups within $8 \mathrm{~min}$ laser irradiation, and the tumor area had a maximum temperature of $49.8 \pm 1.69$ ${ }^{\circ} \mathrm{C}$. However, the temperature of the tumor area was not significantly changed in the PBS groups.

At day 0 , the tumor volume was $66.8 \pm 38.42 \mathrm{~mm}^{3}$, $54.795 \pm 14.76 \mathrm{~mm}^{3}, 59.43 \pm 10.10 \mathrm{~mm}^{3}$, and $68.1 \pm 27.28$ $\mathrm{mm}^{3}$ in the PBS group, PBS with laser irradiation group, HA-IR780 NP, group and HA-IR780 NPs with laser 


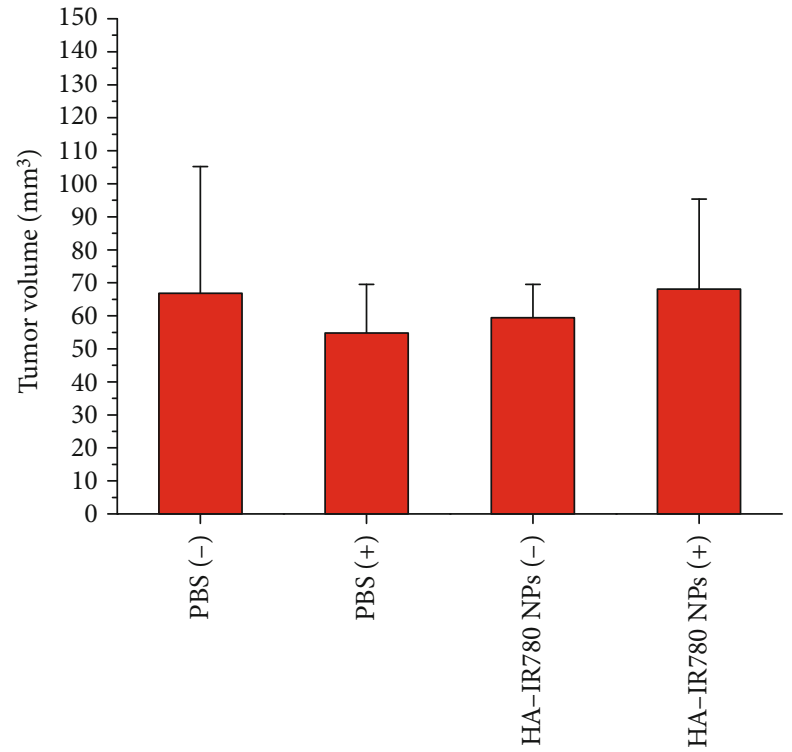

(a)

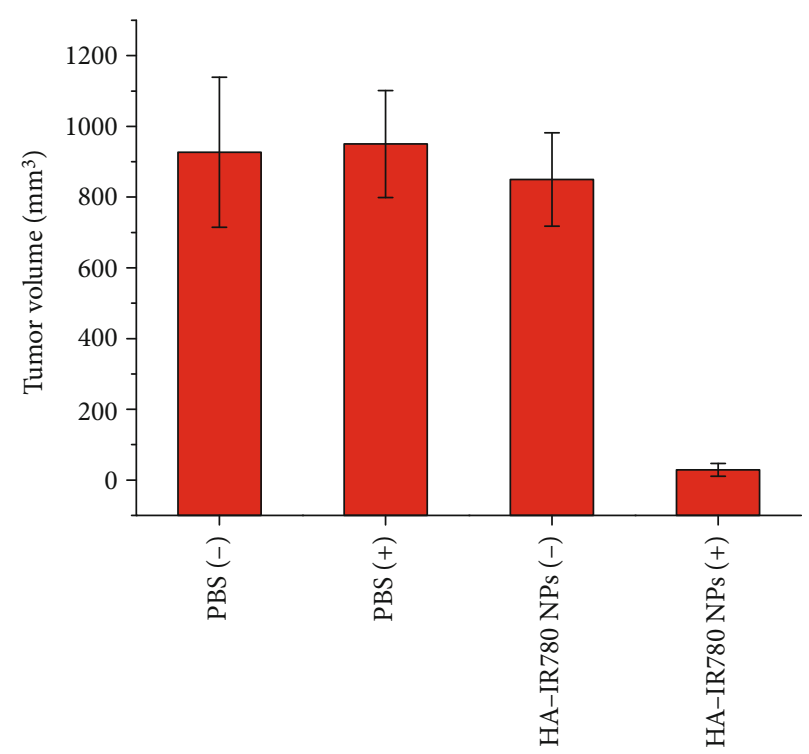

(c)

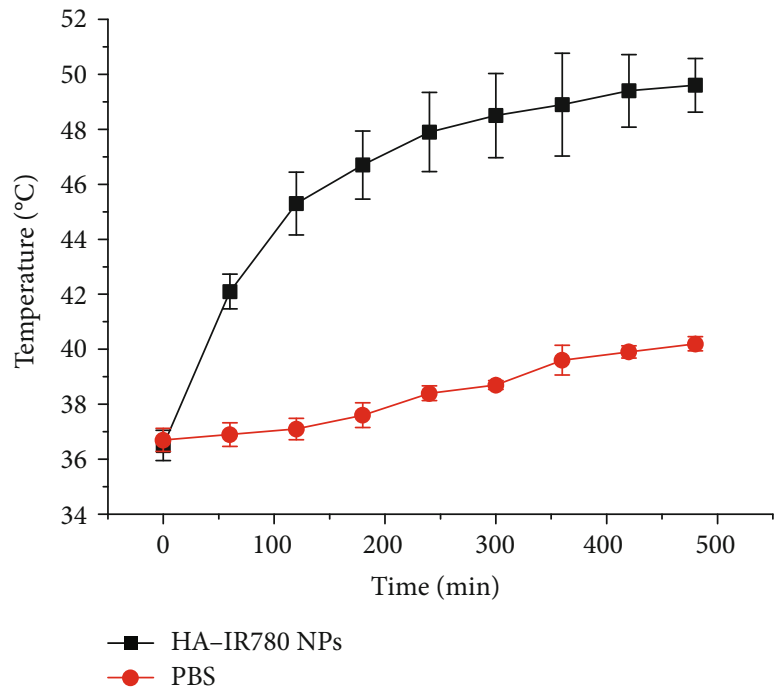

(b)

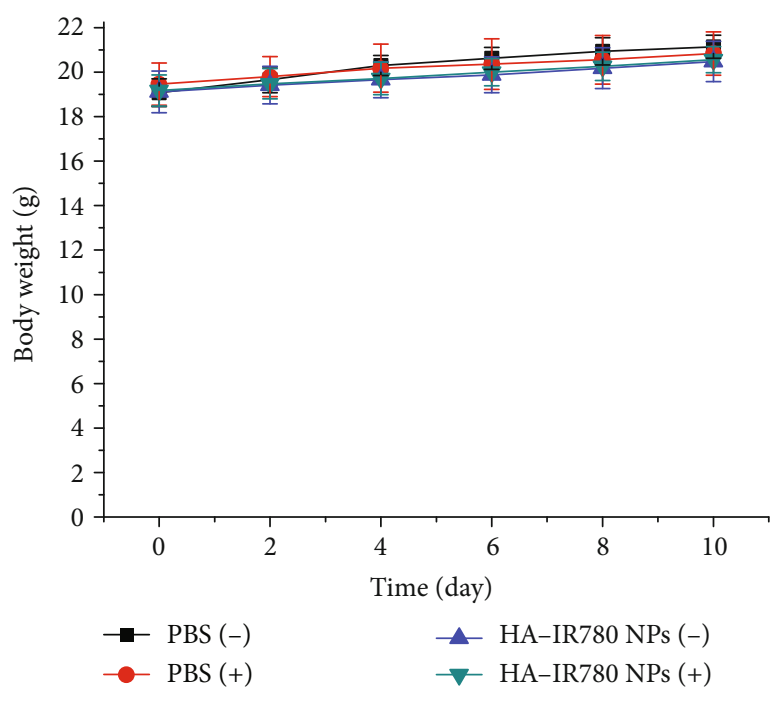

(d)

FIGURE 5: Photothermal therapy for orthotopic renal tumor-bearing mice: (a) tumor volume of mice pretreatment; (b) temperature changes in the tumor area under laser irradiation $\left(808 \mathrm{~nm}, 1 \mathrm{~W} / \mathrm{cm}^{2}, 8 \mathrm{~min}\right)$ after mice were injected with HA-IR780 NPs; (c) tumor volume at 12 days after different treatments; (d) body weight of mice after different treatments.

irradiation group, respectively (Figure 5(a)). At day 12, the tumor size was $926.9 \pm 211.82 \mathrm{~mm}^{3}, 950.1 \pm 151.22 \mathrm{~mm}^{3}$, $849.7 \pm 132.07 \mathrm{~mm}^{3}$, and $28.7 \pm 18.02 \mathrm{~mm}^{3}$ in the PBS group, PBS with laser irradiation group, HA-IR780 NP group, and HA-IR780 NPs with laser irradiation group, respectively (Figure 5(c)). The clear visual images of pre/posttreatment orthotopic renal cancer are shown in Figure 6. All renal tumors were sliced and stained with H\&E; the PBS, PBS with laser, and HA-IR780 NPs without laser groups showed large tumors located in the kidneys. However, in the HA-IR780 NPs with laser irradiation group, only very small residual tumors were located in the kidneys. In addition, there was no significant difference in body weight after the various treatments (Figure 5(d)). The results indicated the excellent photothermal effect on renal tumor ablation.

\section{Conclusion}

We designed the HA-IR780 conjugates, which could selfassemble in water to form HA-IR780 nanoparticles for photothermal ablation of renal tumors. We established a stable orthotopic renal tumor model; the HA-IR780 nanoparticles demonstrated good-tumor targeting property and excellent photothermal effect for renal cancer treatment in the orthotopic renal tumor model. 

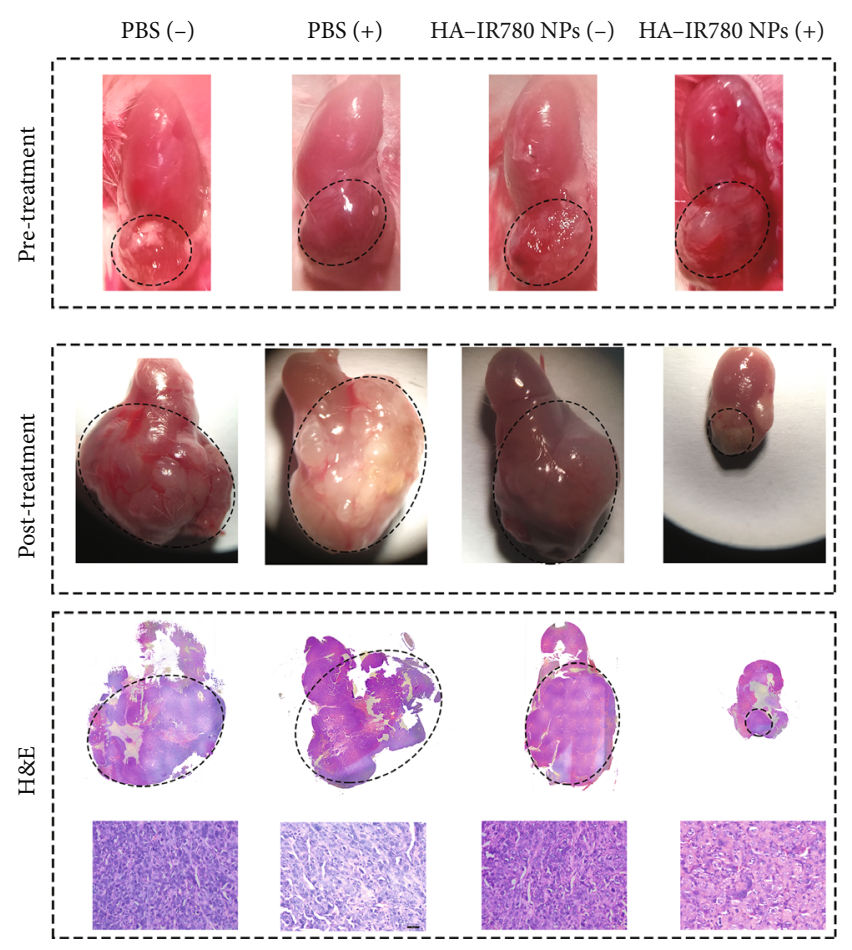

FIGURE 6: Representative images of orthotopic renal cancer at pretreatment and posttreatment and the corresponding H\&Estained renal tumor sections.

\section{Data Availability}

All data generated or analyzed during this study are included in the submitted article.

\section{Conflicts of Interest}

The authors declare no conflicts of interest regarding the publication of this paper.

\section{Acknowledgments}

This work was supported by grants from the National Natural Science Foundation of China (nos. 81972388, 81802532, 81772710,81602221 , and 81802535), the Project of Invigorating Health Care through Science, Technology and Education, Jiangsu Provincial Key Medical Discipline (Laboratory) (ZDXKB2016014), the China postdoctoral fund (223427), the Nanjing Medical Science and Technique Development Foundation (YKK 18064), the Natural Science Foundation of Jiangsu Province (BK20160117), the Jiangsu Provincial Medical Youth Talent (QNRC2016017), and the "Summit of the Six Top Talents” Program of Jiangsu Province (SWYY-084).

\section{References}

[1] L. Albiges, T. Choueiri, B. Escudier et al., "A systematic review of sequencing and combinations of systemic therapy in metastatic renal cancer," European Urology, vol. 67, no. 1, pp. 100110, 2015.
[2] H. Moch, "An overview of renal cell cancer: pathology and genetics," Seminars in Cancer Biology, vol. 23, no. 1, pp. 3-9, 2013.

[3] U. Capitanio and F. Montorsi, "Renal cancer," The Lancet, vol. 387, no. 10021, pp. 894-906, 2016.

[4] E. Scosyrev, E. M. Messing, R. Sylvester, S. Campbell, and H. Van Poppel, "Renal function after nephron-sparing surgery versus radical nephrectomy: results from EORTC randomized trial 30904," European Urology, vol. 65, no. 2, pp. 372-377, 2014.

[5] C. J. Robson, B. M. Churchill, and W. Anderson, "The results of radical nephrectomy for renal cell carcinoma," The Journal of Urology, vol. 197, no. 2S, pp. S111-S113, 2017.

[6] S. P. Psutka, A. S. Feldman, W. S. McDougal, F. J. McGovern, P. Mueller, and D. A. Gervais, "Long-term oncologic outcomes after radiofrequency ablation for T1 renal cell carcinoma," European Urology, vol. 63, no. 3, pp. 486-492, 2013.

[7] J. D. Iannuccilli, D. E. Dupuy, M. D. Beland, J. T. Machan, D. J. Golijanin, and W. W. Mayo-Smith, "Effectiveness and safety of computed tomography-guided radiofrequency ablation of renal cancer: a 14-year single institution experience in 203 patients," European Radiology, vol. 26, no. 6, pp. 1656-1664, 2016.

[8] T. M. Wah, H. C. Irving, W. Gregory, J. Cartledge, A. D. Joyce, and P. J. Selby, "Radiofrequency ablation (RFA) of renal cell carcinoma (RCC): experience in 200 tumours," BJU International, vol. 113, no. 3, pp. 416-428, 2014.

[9] D. Ramirez, Y.-B. Ma, S. Bedir, J. A. Antonelli, J. A. Cadeddu, and J. C. Gahan, "Laparoscopic radiofrequency ablation of small renal tumors: long-term oncologic outcomes," Journal of Endourology, vol. 28, no. 3, pp. 330-334, 2014.

[10] J. L. Hinshaw, M. G. Lubner, T. J. Ziemlewicz, F. T. Lee Jr., and C. L. Brace, "Percutaneous tumor ablation tools: microwave, radiofrequency, or cryoablation-what should you use and why?," Radiographics, vol. 34, no. 5, pp. 1344-1362, 2014.

[11] L. Cheng, C. Wang, L. Z. Feng, K. Yang, and Z. Liu, "Functional nanomaterials for phototherapies of cancer," Chemical Reviews, vol. 114, no. 21, pp. 10869-10939, 2014.

[12] M. A. Mackey, M. R. Ali, L. A. Austin, R. D. Near, and M. A. El-Sayed, "The most effective gold nanorod size for plasmonic photothermal therapy: theory and in vitro experiments," The Journal of Physical Chemistry B, vol. 118, no. 5, pp. 13191326, 2014.

[13] X. Song, H. Gong, S. Yin et al., "Ultra-small iron oxide doped polypyrrole nanoparticles for in vivo multimodal imaging guided photothermal therapy," Advanced Functional Materials, vol. 24, no. 9, pp. 1194-1201, 2014.

[14] S. Wang, P. Huang, L. Nie et al., "Single continuous wave laser induced photodynamic/plasmonic photothermal therapy using photosensitizer-functionalized gold nanostars," Advanced Materials, vol. 25, no. 22, pp. 3055-3061, 2013.

[15] T. S. Lin, A. Yuan, X. Z. Zhao et al., "Self-assembled tumortargeting hyaluronic acid nanoparticles for photothermal ablation in orthotopic bladder cancer," Acta Biomaterialia, vol. 53, pp. 427-438, 2017.

[16] Q. Chen, L. Xu, C. Liang, C. Wang, R. Peng, and Z. Liu, "Photothermal therapy with immune-adjuvant nanoparticles together with checkpoint blockade for effective cancer immunotherapy," Nature Communications, vol. 7, no. 1, article 13193, 2016.

[17] M. N. Collins and C. Birkinshaw, "Hyaluronic acid based scaffolds for tissue engineering-a review," Carbohydrate Polymers, vol. 92, no. 2, pp. 1262-1279, 2013. 
[18] J. Lam, W. E. Lowry, S. T. Carmichael, and T. Segura, "Delivery of iPS-NPCs to the stroke cavity within a hyaluronic acid matrix promotes the differentiation of transplanted cells," Advanced Functional Materials, vol. 24, no. 44, pp. 70537062, 2014.

[19] Y. Zhong, J. Zhang, R. Cheng et al., "Reversibly crosslinked hyaluronic acid nanoparticles for active targeting and intelligent delivery of doxorubicin to drug resistant CD44+ human breast tumor xenografts," Journal of Controlled Release, vol. 205, pp. 144-154, 2015.

[20] F. Zamboni, S. Vieira, R. L. Reis, J. Miguel Oliveira, and M. N. Collins, "The potential of hyaluronic acid in immunoprotection and immunomodulation: chemistry, processing and function," Progress in Materials Science, vol. 97, pp. 97-122, 2018.

[21] K. Valachová, D. Topol’ská, R. Mendichi, M. N. Collins, V. Sasinková, and L. Šoltés, "Hydrogen peroxide generation by the Weissberger biogenic oxidative system during hyaluronan degradation," Carbohydrate Polymers, vol. 148, pp. 189193, 2016.

[22] K. Valachová, M. Baňasová, D. Topol'ská et al., "Influence of tiopronin, captopril and levamisole therapeutics on the oxidative degradation of hyaluronan," Carbohydrate Polymers, vol. 134, pp. 516-523, 2015.

[23] F. Zamboni, M. Keays, S. Hayes et al., "Enhanced cell viability in hyaluronic acid coated poly (lactic-co-glycolic acid) porous scaffolds within microfluidic channels," International Journal of Pharmaceutics, vol. 532, no. 1, pp. 595-602, 2017.

[24] M. N. Collins, Hyaluronic acid for biomedical and pharmaceutical applications, Smithers Rapra, 2014.

[25] C. Yue, P. Liu, M. Zheng et al., "IR-780 dye loaded tumor targeting theranostic nanoparticles for NIR imaging and photothermal therapy," Biomaterials, vol. 34, no. 28, pp. 6853-6861, 2013.

[26] E. Zhang, S. Luo, X. Tan, and C. Shi, "Mechanistic study of IR780 dye as a potential tumor targeting and drug delivery agent," Biomaterials, vol. 35, no. 2, pp. 771-778, 2014. 